\title{
On nonassociative effects of auditory CSs on avoidance behavior
}

\author{
ALBERT E. ROBERTS \\ Catawba College, Salisbury, North Carolina 28144
}

\begin{abstract}
The nonassociative (i.e., sensitization) effect of a discontinuous tone and a clicking CS was studied in rats by comparing free operant avoidance measures obtained during a CS-pretest phase with measures from CS-US and CS-extinction phases. The clicking CS, but not the tone, was found to produce markedly enhanced avoidance behavior during the pretest. Both CSs, however, acquired suppressive control over avoidance under CS-US training. When the US was removed for CS extinction, each CS recovered the kind of influence over avoidance present during the pretest. The sensitization influence of the clicker was discussed as arising from an interaction between unavoided shocks from the avoidance schedule with the abrupt-onset property of that stimulus (and a property not present in a tone).
\end{abstract}

The present study evolved from reports that avoidancemaintained behavior, originally suppressed during a stimulus (CS) followed by shock(US), becomes enhanced when that US subsequently is removed; moreover, this enhanced avoidance behavior is maintained throughout the CS-extinction phase (see review by Hurwitz \& Roberts, 1977). An extinction of effect to the CS, in the traditional sense of the CS's coming to have "minimal influence" over behavior, does not materialize. The US need not be removed, as enhanced avoidance behavior also develops when the CS and US are separated by inserting a second stimulus between the two (i.e., an S1-S2-US arrangement; Roberts \& Hurwitz, 1979). With few exceptions (cf. Riess \& Farrar, 1973), the enhancement in avoidance behavior has not received direct experimental investigation but, typically, is reported in a context of demonstrating that avoidance suppression fades when the US is omitted (cf. Hurwitz \& Roberts, 1971).

Direct interest in the "conditioned" enhancement of avoidance within our laboratory has been stimulated by the possibility that the CS-US and CS-extinction procedures might control reliable, but opposite, changes in avoidance behavior. Recent work, however, has raised an alternate possibility (Roberts, Note 1, Note 2). Enhanced avoidance was obtained during the CS (with US omitted) when superimposed on an avoidance baseline but not obtained when the CS was given on an avoidance-extinction baseline. In the latter instance, the CS actually showed "minimal influence" on avoidance behavior. This finding suggests that enhanced avoidance behavior under the CS-extinction procedure might not reflect an associative process but might stem from

This research was supported by a grant from the Grants and Research Committee of Catawba College. Reprints may be obtained from the author, Department of Psychology, Catawba College, Salisbury, North Carolina 28144. a nonassociative interaction between the CS and unavoided shocks arising from the avoidance schedule (i.e., the subject's becoming sensitized to the CS).

Kling (1971) discusses sensitization in terms of an increase in the reactivity of a subject to a CS, not originally neutral in effect, by presentations of the US. Moreover, the possibility of a sensitization artifact is magnified when an aversive US is used. The presence of this nonassociative property of the CS could pass unnoticed, as the CS may not be offered in a pretest phase prior to CS-US associations. ${ }^{1}$ This procedural omission likely reflects a concern over possible attenuating influences that a preexposed CS might have on the development of conditioned avoidance suppression (cf. Carlton \& Vogel, 1967). An estimate about the effect sensitization may have on an avoidance baseline (and subsequent conditioned avoidance suppression/enhancement phenomena) is difficult to make, as such effects are relatively undocumented. The experiment described below addressed this issue by (1) using two auditory CSs (a tone and a clicking stimulus) and (2) including a CS-pretest phase prior to the CS-US associations.

\section{METHOD}

\section{Subjects}

Twelve female hooded rats, obtained from Blue Spruce Farms, New York, served as subjects. The rats were experimentally naive and weighed about $150 \mathrm{~g}$ at the beginning of avoidance training.

\section{Apparatus}

Three standard LVE operant chambers (Model 143-2), measuring $25 \times 27 \times 30 \mathrm{~cm}$ were used. Each was modified by placing a light assembly in the center of the Plexiglas ceiling to serve as a houselight. The floor grids were replaced with $.25-\mathrm{cm}$ brass rods spaced $1.3 \mathrm{~cm}$ apart parallel to the width of the lever. Other standard assemblies that protruded into the chamber were removed. A $3 \times 1 \mathrm{~cm}$ lever was located in the center of the intelligence panel and extended $2.5 \mathrm{~cm}$ into the chamber, $6 \mathrm{~cm}$ above the grid floor. A deadweight of $36 \mathrm{~g}$ 
$(.36 \mathrm{~N})$ on the lever operated the microswitch. Shock was delivered from a constant-current generator (BRS Model SG-901) via a scrambler (BRS Model SC-901) to the grids, lever, and metal sides of the chamber.

An uncovered DPDT relay was attached to the outside of the intelligence panel and operated at 6 times/sec to serve as the clicking CS. Electrical tape was placed on the relay contacts and the electromagnet to dampen the clicking sound. A $2,800-\mathrm{Hz}$ Mallory Sonalert also was attached to the outside of the intelligence panel (facing away from the chamber), with a $3-\mathrm{cm}$ foam rubber pad placed over the speaker surface. The Sonalert also was activated at 6 times/sec to give a discontinuous tone CS.

Each chamber was placed in a sound-attenuated box, with a blower fan providing ventilation and a masking noise $(75 \mathrm{~dB}$, SPL). The clicking and tone $\mathrm{CS}$ added $5 \mathrm{~dB}$ and $3 \mathrm{~dB}$, respectively, to this background noise level. All programming and recording equipment were in an adjoining room.

\section{Procedure}

The rats were trained under a free operant avoidance schedule whereby each leverpress postponed shock for $15 \mathrm{sec}$ and briefly $(.3 \mathrm{sec})$ turned off the houselight. If the 15 -sec period elapsed, a $.3-\mathrm{sec} 1-\mathrm{mA}$ shock occurred every $5 \mathrm{sec}$. This avoidance schedule remained in effect throughout the experiment. After $202-\mathrm{h}$ avoidance training sessions, the rats were arranged into two groups (each $n=6$ ) so that the mean response and shock rates from the final five-training sessions were comparable.

A CS-pretest phase was given (five sessions), with one group receiving the clicking $\mathrm{CS}$ and the other the tone CS. In each case, the 1-min CS was superimposed on avoidance behavior 20 times during the session on the average of once every $6 \mathrm{~min}$ (range: $2.5-12 \mathrm{~min}$ ). The first CS occurred about $7 \mathrm{~min}$ after the session began. The CS-US training phase (20 sessions) immediately followed. The arrangements were identical to those of the pretest phase, except that a 1-sec 1-mA shock US followed each CS. In the CS-extinction phase (10 sessions), the shock US was not given (i.e., a procedure similar to the pretest). Finally, the shock US again followed each CS in a second CS-US phase (10 sessions).

\section{RESULTS}

The changes in avoidance behavior over each phase of the experiment are summarized in Figure 1 in terms of mean response and shock rates for the two groups. The enhancement in avoidance to the clicking CS during the pretest was clear: Mean response rate was increased by $75 \%$ over baseline, and shock rate was reduced by over $67 \%$. However, neither measure was affected by the tone. Pairing the CSs with shock in the CS-US phase led to several general changes in avoidance. First, the baseline performance of both groups was adversely affected compared with both avoidance training and the pretest phases. Second, compared specifically with the pretest measures, CS-US training led to a reduction in the response rates of both groups during the CSs. Third, the avoidance of shock during both CSs, in terms of shock rate, had worsened compared with pretest levels, as well as with the CS-US baselines. Fourth, removing the US led to an increase in response rate in the clicking CS periods but not in the tone CS; however, shock rates in both CSs decreased below their respective baselines. Finally, reinstating the shock US

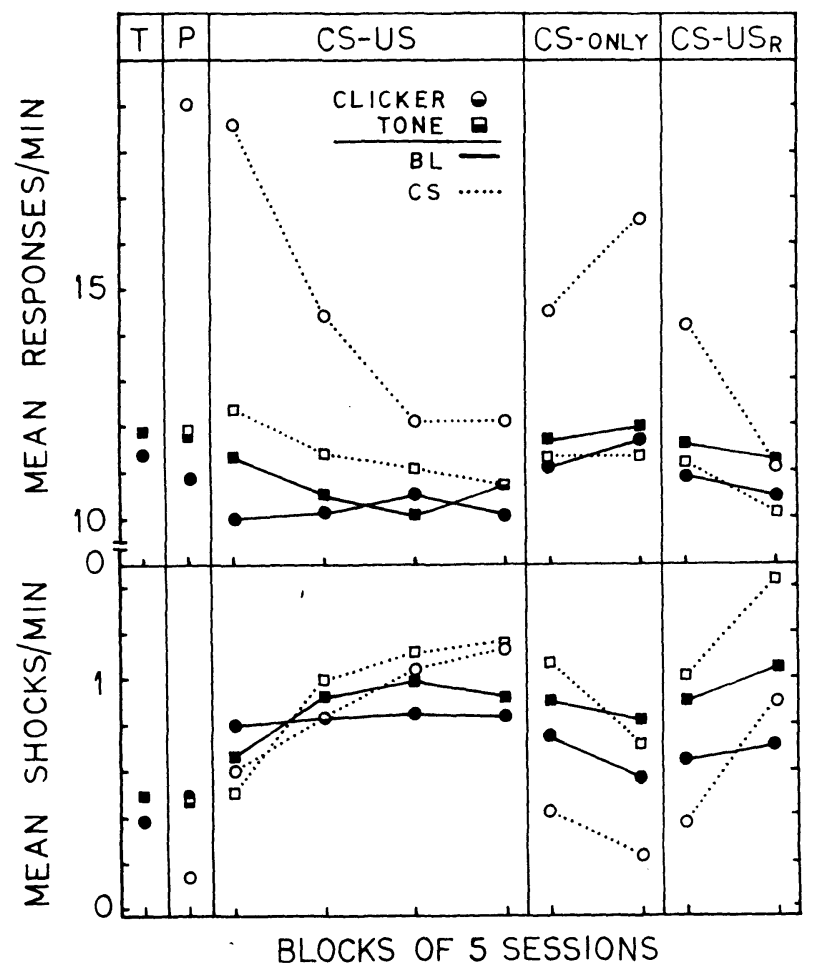

Figure 1. Mean response and shock rates for the rats trained under the clicking or tone CS. Means are given for the final five sessions of avoidance training (T) and the pretest (P) phases and in blocks of five sessions of the CS-US, CS-only, and CS-US replication phases.

produced a reversal in trend: The avoidance of both groups again deteriorated during $\mathrm{CS}$, compared with baseline measures.

To statistically gauge the influence of the two CSs on avoidance, separate inflection ratios were obtained for the response and shock rate values for each subject based on the final five sessions of each phase (i.e., mean CS value/mean baseline value). These ratio values then were analyzed by separate 2 by 4 ANOVAs using the four CS phases as a repeated-measures factor. Compared with the tone, the clicking CS produced larger response ratios $[\mathrm{F}(1,10)=12.415, \mathrm{p}<.001]$; moreover, larger ratios were obtained from CS only (including the pretest) than from CS-US $[\mathrm{F}(3,36)=42.530, \mathrm{p}<.001]$. Finally, the source of the CS by Phase interaction $[F(3,36)=$ $32.558, \mathrm{p}<.001]$ was that the clicking CS led to larger ratios than the tone did in each of the two CSonly phases. The ANOVA on the shock-ratio values indicated that, overall, differences in ratios between the two CSs were unreliable $(\mathrm{F}<1)$; shock ratios under the CS-US phases were reliably larger than in the CSonly phases $[F(3,36)=23.156, p<.001]$. Finally, a significant CS by Phase interaction $[F(3,36)=3.172$, $\mathrm{p}<.05$ ] reflected smaller shock ratios to the clicking CS during the CS-only phases. 


\section{DISCUSSION}

The data demonstrated that the clicking CS, given prior to CS-US training, enhanced avoidance behavior when superimposed on the avoidance baseline. Moreover, although it is not apparent from Figure 1, the degree of avoidance enhancement showed no sign of diminishing over the five pretest sessions (i.e., $100 \mathrm{CS}$ presentations). On the other hand, the tone CS was essentially "neutral" in effect throughout the pretest phase. CS-US training obviated the enhancement influence of the clicking CS as suppressive control over avoidance behavior was acquired, as indexed by an increase in unavoided shocks during the CS. The tone also acquired a suppressive function when given as a preshock CS. Interestingly, the tone did not come to exert a stronger suppressive effect than the clicker, even though pretest differences between the two were pronounced. When the US was removed in the CS-extinction phase, both CSs not only lost suppressive control but also recovered the kind of influence present in the pretest that preceded CS-US training.

As noted earlier, sensitization to the clicking CS probably followed from an interaction between the clicker and unavoided shocks. But why does sensitization occur to the clicking CS but not to the tone? The reason may rest with differences between the onset properties of the two stimuli. The clicking stimulus was produced by the sudden contact of two surfaces, and, thus, it had a rather abrupt onset. On the other hand, the discontinuous tone had a more gradual onset, in that a finite "rise time" seems to be a property of tone stimuli. Abruptness of stimulus onset is an important factor in producing an acoustic startle reaction (although such a reaction is typically evoked by sound levels more intense than those in the present experiment) and may be just as important in the production of sensitized avoidance enhancement. (The reader is directed to Ison, 1978, for a more detailed discussion of the abruptness factor; particularly, see his Figure 1.)

If sensitization to a clicking CS contributes to the enhancement of avoidance behavior, an assumption that this nonassociative influence is removed simply by delivering the clicker in a pretest clearly is not justified. The enhanced avoidance behavior in the initial CS-US training sessions likely reflects this sensitization influence (compare the first block of CS-US sessions with the pretest in Figure 1). But even if the nonassociative influences are not eliminated, a pretest phase can provide as valuable a context for evaluating the effects of CS-US training on avoidance as within-session comparisons (i.e., CS with baseline measures).

\section{REFERENCE NOTES}

1. Roberts, A. E. Pursuing an anomaly: When extinction does not extinguish a fear CS. Paper presented at the annual meeting of the Southeastern Psychological Association, Atlanta, 1978.

2. Roberts, A. E. On the unconditional effects of conditional stimuli. Paper presented at the annual meeting of the Southeastern Psychological Association, New Orleans, 1979.

\section{REFERENCES}

Carlton, P. L., \& Vogel, J. R. Habituation and conditioning. Journal of Comparative and Physiological Psychology, 1967, 63, 348-351.

Hurwitz, H. M. B., \& Roberts, A. E. Conditioned suppression of an avoidance response. Journal of the Experimental Analysis of Behavior, 1971, 16, 275-281.

Hurwitz, H. M. B., \& Roberts, A. E. Aversively controlled behavior and the analysis of conditioned suppression. In $\mathrm{H}$. Davis \& H. M. B. Hurwitz (Eds.), Operant-Pavlovian interactions. Hillsdale, N.J: Erlbaum, 1977.

Ison, J. R. Reflex inhibition and reflex elicitation by acoustic stimuli differing in abruptness of onset and peak intensity. Animal Learning \& Behavior, 1978, 6, 106-110.

KLING, J. W. Learning: Introductory survey. In J. W. Kling \& L. A. Riggs (Eds.), Woodworth and Schlosberg's experimental psychology (3rd ed.). New York: Holt, Rinehart \& Winston, 1971.

RIESS, D., \& FARRAR, C. H. UCS duration, conditioned acceleration, multiple CR measurement and Pavlovian R-R laws. Journal of Comparative and Physiological Psychology, 1973, 82, 144-151.

Roberts, A. E., \& Hurwitz, H. M. B. The conditioned suppression and enhancement of avoidance during a serial compound CS. Bulletin of the Psychonomic Society, 1979, 14, 7-10.

\section{NOTE}

1. Many experiments do include pretest phases prior to CSUS association, but data from this phase often are not presented.

(Received for publication January 3, 1982.) 